\title{
Adenocarcinoma in Barrett's oesophagus: an overrated risk
}

\author{
A H VAN DER VEEN, J DEES, J D BLANKENSTEIJN,* \\ AND M VAN BLANKENSTEIN \\ From the Department of Internal Medicine II and Department of Surgery, * University Hospital Rotterdam, \\ Rotterdam, The Netherlands
}

SUMMARY Barrett's oesophagus is a risk factor for the development of oesophageal cancer and for this reason annual endoscopic surveillance has been proposed. In this retrospective study of all patients with Barrett's oesophagus diagnosed in a 12 year period carcinoma had developed in only four patients. The incidence of oesophageal cancer in this series was one in 170 patient years, which means a 30-fold increase compared with the general population. The survival of patients with Barrett's oesophagus was not different, however, from an age and sex matched control population. It is concluded that systematic endoscopic surveillance of patients with Barrett's oesophagus is not indicated.

Barrett's oesophagus is a risk factor for the development of oesophageal carcinoma. ${ }^{1-10}$

In a series of 538 patients seen by the Rotterdam Oesophageal Carinoma Group the tumour was localised in Barrett's oesophagus in 55 cases: 10\%." This relatively strong correlation, however, gives no indication about the size of the risk of developing carcinoma in Barrett's oesophagus.

The prevalence of oesophageal cancer in patients with Barrett's oesophagus is sometimes erroneously advanced as an indicator of the size of this risk. The prevalence varies from 2.5 to $46 \%$ (33\% in our series) and mainly reflects patients selection. ${ }^{12-14}$

Two retrospective American surveys were recently published, which showed a 30 to 40 -fold increased risk of oesophageal carcinoma in patients with Barrett's oesophagus. ${ }^{15} 16$

The usefulness of annual endoscopic examination of patients with Barrett's oesophagus has been debated: although Spechler seems to voice some scepticism in his article: 'Adenocarcinoma and Barrett's oesophagus. An overrated risk?', almost all

Address for correspondence: Jan Dees, MD, Department of Internal Medicine II, University Hospital Rotterdam, Dr Molewaterplein 40, 3015 GD Rotterdam, The Netherlands.

Received for publication 8 July 1988. authors have stressed the importance of annual endoscopic surveillance. ${ }^{15}$

The purpose of the present study was to investigate the incidence of oesophageal carcinoma in a group of patients with Barrett's oesophagus and to look for possible subgroups with increased risk.

\section{Methods}

PATIENTS

Data were collected about all patients in whom the diagnosis of Barrett's oesophagus had been made during the period between November 1973 and May 1986. All endoscopies were carried out or supervised by two of us (JD and MvB), each with experience of over 10000 endoscopies. The following entry criteria were used in this study: (1) Barrett's oesophagus had to be present over at least $3 \mathrm{~cm}$ of the full circumference of the oesophagus. (2) Patients with carcinoma of the oesophagus were excluded. (3) The duration of the follow up had to be at least three months in order to avoid diagnostic problems arising from oesophageal strictures or ulcers in Barrett's oesophagus.

Barrett's oesophagus was arbitrarily classified as 'extended' if at least $8 \mathrm{~cm}$ of uninterrupted cylindrical epithelium was diagnosed. The general practitioners of the patients were questioned by post, and where 
necessary extra information was obtained from the general practitioners or the patients by telephone. Supplementary medical data, such as the nature of previous gastric surgery, were obtained from the case notes. The length of follow up was calculated from the date of the first endoscopy at which the diagnosis Barrett's oesophagus was established until the date of the last follow up information. The incidence of oesophageal cancer in this series of patients with Barrett's oesophagus was calculated and this figure was compared with the incidence of oesophageal carcinoma in the population of the Netherlands in the same age groups (data obtained from the report Mortality according to primary causes, age and sex for the year 1985 of the Central Bureau of Statistics).

Survival was assessed by computerised life table analysis as described by Kaplan and Meier. ${ }^{17}$ In addition this curve was compared with the mean survival of the Dutch population, matched for age, sex, and year of diagnosis.

\section{Results}

One hundred and sixty six patients met the intake criteria. Their mean age was 62 years (14-96 years). There were 97 men and 69 women. The response by the general practitioners to the interview was $93 \%$ (concerning 155 of the 166 patients). Thirty five patients had died during the follow up period, two from oesophageal cancer, and 33 from other causes.

Of the 120 surviving patients, two had developed carcinoma of the oesophagus. These four carcinomas were diagnosed between 12 and 72 months after the endoscopic diagnosis of Barrett's oesophagus.

\section{CASE HISTORIES OF THE FOUR PATIENTS WITH CARCINOMA}

\section{Patient A (male)}

In 1975 at the age of 68 years the diagnosis of an ulcer in Barrett's oesophagus was made. He was treated by antrectomy and Roux-en-Y anastomosis. In 1979 gastroscopy was repeated for dysphagia and vomiting of food; an adenocarcinoma of the oesophagus was found. The patient refused further analysis and treatment. He died in 1981 from a myocardial infarction.

\section{Patient B (male)}

In 1977 at the age of 67 years an ulcer in Barrett's oesophagus was diagnosed. Because medical treatment failed antrectomy was carried out in 1978. In 1982 an adenocarcinoma of the oesophagus was found for which the patient was treated by radiotherapy and surgery. He died two months later from postoperative complications.

\section{Patient C (male)}

This patient had an antireflux procedure in 1965 at the age of 36 years. In 1968 an antrectomy was done for duodenal ulceration, in 1970 followed by a vagotomy. In view of persistent complaints of vomiting a Roux-en-Y anastomosis was carried out in 1980. At pre-operative gastroscopy Barrett's oesophagus was diagnosed. The complaints failed to improve and 12 months later a carcinoma in situ was found in Barrett's oesophagus. An oesophageal resection with colon interposition was carried out. Five years later the patient was well and there were no signs of metastasis or recurrence.

\section{Patient $D$ (female)}

She underwent a Nissen fundiplication at the age of 75 years in 1976 for an ulcer in Barrett's oesophagus. Six years later she again attended the outpatient department for retrosternal pain. At endoscopy an adenocarcinoma in Barrett's oesophagus was diagnosed. A resection with gastric tube reconstruction was undertaken in this now 81 year old lady. Five years later she was well and without any signs of metastasis or recurrence.

\section{COMMON FEATURES}

The common features of the patients in whom carcinoma of the oesophagus developed were: (1)

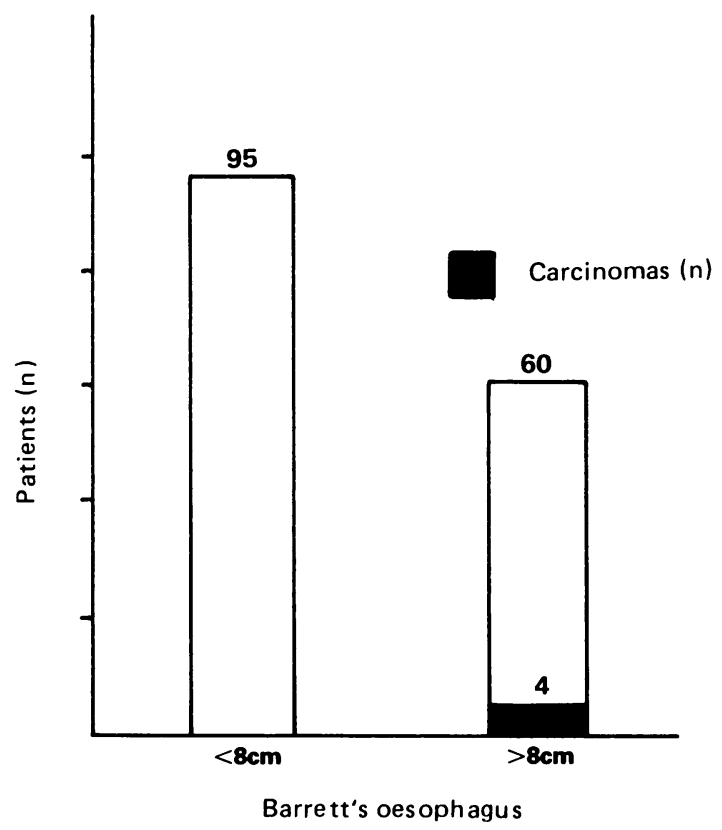

Fig. 1 Number of patients with 'extended' Barrett's oesophagus $(\geqslant 8 \mathrm{~cm})$ in relation to the number of developing carcinomas 


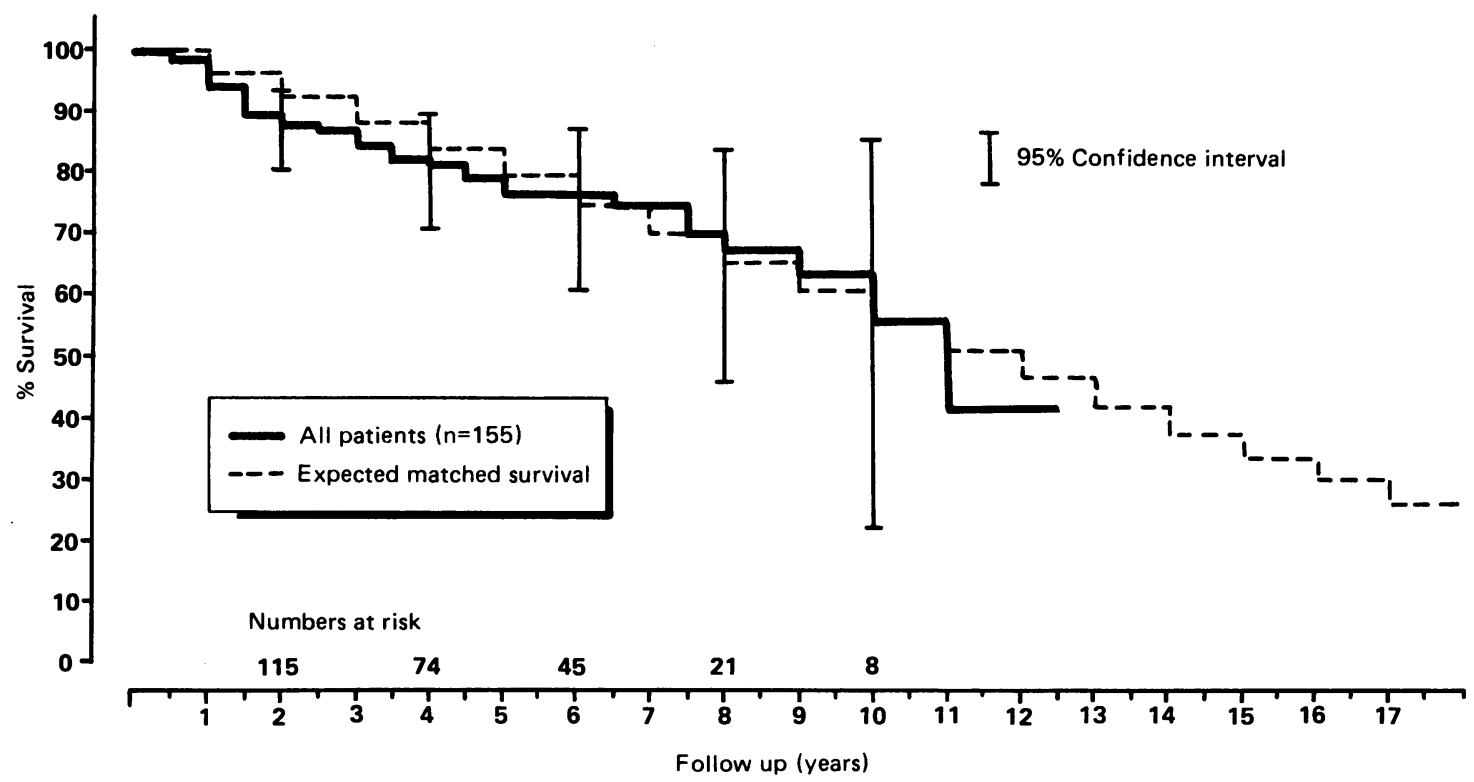

Fig. 2 Survival curve from time of diagnosis of Barrett's oesophagus.

There was at least $10 \mathrm{~cm}$ Barrett's oesophagus present in all four patients against 60 patients with extended Barrett's oesophagus in the total series (Fig. 1). (2) All four patients had undergone previous gastric surgery, against $\mathbf{4 0}$ in $\mathbf{1 5 5}$ of the total series. (3) Three patients had been treated for an ulcer in Barrett's oesophagus against 58 of 155 in the total series.

INCIDENCE OF OESOPHAGEAL CANCER IN

PATIENTS WITH BARRETT'S OESOPHAGUS

The total follow up time was 681 patient years. The incidence of oesophageal carcinoma in this series was therefore one in 170 patient years. The mean follow up was 4.4 years (three months to 12 years and five months).

INCIDENCE OF OESOPHAGEAL CANCER IN THE POPULATION

The annual mortality from carcinoma of the oesophagus in the Dutch population between 60 and 64 years is for men $210: 10^{6}$ and for women $50: 10^{6} .^{18}$

The expected mortality in our series of patients with Barrett's oesophagus was:

$$
\begin{aligned}
& \frac{\text { number of men }}{\text { number of women }} \times \frac{\text { incidence in men }+ \text { incidence in women }}{2}= \\
& \frac{97}{69} \times \frac{210+50}{2}=185 \text { per } 10^{\circ} \text { annually. }
\end{aligned}
$$

Although the prognosis of carcinoma of the oesophagus is unfavourable, the incidence is presumably somewhat higher than mortality, so that an annual incidence of $200: 10^{6}$ could be expected in our series. This would amount to one carcinoma per 5000 patient years.

\section{INCREASED RIS K}

The increased risk for carcinoma of the oesophagus in our group of patients with Barrett's oesophagus was therefore $5000: 170=30$ fold.

SURVIVAL CURVE

There was no significant difference between the survival curves of the follow up population and that of an age and sex matched group from the general population (Fig. 2).

Table Results of three retrospective follow up studies of the incidence of oesophageal carcinoma in patients with Barrett's oesophagus

\begin{tabular}{lccc}
\hline & $\begin{array}{l}\text { Boston VA } \\
\text { Hospital }\end{array}$ & $\begin{array}{l}\text { Mayo } \\
\text { Clinic }\end{array}$ & $\begin{array}{l}\text { AZR } \\
\text { Rotterdam }\end{array}$ \\
\hline Patients (n) & 105 & 104 & 155 \\
Follow up in years & $3 \cdot 3$ & $8 \cdot 5$ & $4 \cdot 4$ \\
Carcinomas & 2 & 2 & 4 \\
Incidence & $1: 175$ & $1: 441$ & $1: 170$ \\
Increased risk & $40 \times$ & $30 \times$ & $30 \times$ \\
\hline
\end{tabular}




\section{Discussion}

We report the results of the first European survey of the incidence of oesophageal cancer in patients with Barrett's oesophagus. In the Table our results are compared with similar longitudinal retrospective surveys by Spechler from Boston and Cameron from Rochester. ${ }^{1516}$ The incidence of one carcinoma in $\mathbf{1 7 0}$ patient years found in our study, is in the same range as the American findings of respectively one in 175 and one in 441 patient years. Our findings indicate a 30 -fold increased risk in comparison with a control population in the same age group. Barrett's oesophagus is therefore a risk factor for the development of carcinoma of the oesophagus.

The question about the usefulness of annual endoscopic surveillance in patients with Barrett's oesophagus in order to detect dysplasia and early carcinoma was raised 10 years ago. Most authors have tended to recommend this annual examination, but not always with full conviction. This advise was often based on a tendency to confuse prevalence with incidence. As carcinoma of the oesophagus is a relatively rare disease, a 30 to 40 -fold increased risk needs not necessarily influence life expectancy. This becomes more obvious when the data from the three series are pooled. At a mean age of 65 years only eight of the 364 patients with Barrett's oesophagus $(2 \cdot 2 \%)$ had developed carcinoma of the oesophagus during a mean follow up of $5 \cdot 3$ years (Table). Carcinoma of the oesophagus was the cause of death in only three of the 76 patients with Barrett's oesophagus, who died during this period. The mean age of death in our series was 74.6 years, in the Mayo Clinic study 73 years. Therefore most patients with Barrett's oesophagus died in ripe old age and only sporadically from carcinoma of the oesophagus. Our study and that of Cameron failed to show a difference in survival between patients with Barrett's oesophagus and a control population (Fig. 2). ${ }^{16}$ Therefore Barrett's oesophagus does not significantly influence survival.

The conclusion from these data is that there are no arguments to submit all patients with Barrett's oesophagus to annual endoscopic surveillance.

There are, however, indications that there are subgroups of patients which are specially at risk:

\section{EXTENDED COLUMNAR LINED OESOPHAGUS}

Harle and Ransom have suggested that extensive Barrett's oesophagus could be an extra risk factor. ${ }^{19} 20$ In our series extensive Barrett's oesophagus was present in 60 of 155 patients, four of whom developed carcinoma. No tumours were seen in 97 patients with less than $8 \mathrm{~cm}$ of columnar lined oesophagus (Fig. 1).
HIGH GRADE DYSPLASIA

High grade dysplasia is often found in conjunction with an adenocarcinoma in Barrett's oesophagus (68-100\%), but only in a minority of patients without carcinoma ${ }^{21}$ It is certainly advisable to monitor these patients closely by endoscopy and possibly consider oesophageal resection..$^{22}$

\section{INTESTINAL TYPE OF EPITHELIUM}

Carcinomas in Barrett's oesophagus are usually surrounded by 'specialised intestinal epithelium'. This is found in only a third of subjects with Barrett's oesophagus without carcinoma. ${ }^{23}$

PREVIOUS GASTRIC SURGERY AND BARRETT'S ULCER Our data suggest that a history of previous gastric surgery and a history of Barrett's ulcer may be more frequent in patients with carcinoma in Barrett's oesophagus, but in view of the small numbers more data would have to be collected.

\section{SMOKING AND ALCOHOL}

Smoking and alcohol are usually considered to be risk factors for the development of carcinoma of the oesophagus. Spechler found indications that this was also the case in patients with Barrett's oesophagus. ${ }^{\text {is }}$

Except high grade dysplasia, the relative importance of these potential risk factors remains to be established. Endoscopic surveillance studies have so far only been published as abstracts. ${ }^{24} 25$ These studies seem to be carried out in selected patients with Barrett's oesophagus and the higher incidence of oesophageal cancer in these series - which probably include more patients with extra risk factors appears to sustain the presumption that subgroups exist, in which endoscopic surveillance has a higher yield.

It is concluded that systematic endoscopic surveillance in patients with Barrett's oesophagus is not indicated, but that from future research subgroups which are specially at risk may emerge.

\section{References}

1 Raphael HA, Ellis FH, Dockerty MB. Primary adenocarcinoma of the esophagus: 18-year review and review of literature. Ann Surg 1966; 164: 785-6.

2 Jernstrom P, Brewer LA. Primary adenocarcinoma in the mid-esophagus arising in ectopic gastric mucosa with associated hiatal hernia and reflux esophagitis (Dowson's syndrome). Cancer 1970; 26: 1343-8.

3 Burns WA, Flores PA, Moshyedi A, et al. Clinical conditions associated with columnar-lined esophagus. Dig Dis 1970; 15: 607-15.

4 Shafer RB. Adenocarcinoma in Barrett's columnar epithelial lined esophagus. Arch Surg 1971; 103: 411-3.

5 Hawe A, Payne WS, Weiland LH, et al. Adeno- 
carcinoma in columnar epithelial lined lower (Barrett) esophagus. Thorax 1973; 28: 511-4.

6 Hankins JR, Cole FN, Attar S, et al. Adenocarcinoma involving the esophagus. J Thorac Cardiovasc Surg 1974; 68: 148-58.

7 Belladonna JA, Hajdu ST, Bains MS, et al. Adenocarcinoma in situ of Barrett's esophagus diagnosed by endoscopic cytology. N Engl J Med 1974; 291: 895-6.

8 Stillman AE, Selwyn JI. Primary adenocarcinoma of the esophagus arising in a columnar-lined esophagus. Dig Dis 1975; 20: 577-82.

9 Lortat-Jacob JL, Maillard JN, Richard CIA, et al. Primary esophageal adenocarcinoma: report of 16 cases. Surgery 1967; 64: 535-43.

10 Sjøgren RW, Johnson LF. Barrett's esophagus: a review. Am J Med 1983; 74: 313-21.

11 Dees J. Carcinoma in Barrett's oesophagus, with results of treatment in 65 patients. In: Eds. Yap SH, Sluis RFVD, Lamers CBHW. Recent advances in diagnostic and therapeutic endoscopy. Aalsmeer: MurKostverloren, 1984: 6-13.

12 Naef AP, Savary M, Azzello L. Columnar-lined lower esophagus: an acquired lesion with malignant predisposition. J Thorac Cardiovasc Surg 1975; 70: 826-35.

13 Skinner DB. The columnar-lined esophagus and adenocarcinoma. Ann Thorac Surg 1985; 40: 321-2.

14 Dees J. De Barrett-oesophagus als risicofactor voor het slokdarmcarcinoom. In: Eds Alleman, MJA, Weterman, IT, Lamers, CBHW. Maag-, Darm-en Leverziekten. Mur-Kostverloren, 1986: 31-6.
15 Spechler SJ, Robbins AH, Rubins HB, et al. Adenocarcinoma and Barrett's esophagus: an overrated risk? Gastroenterology 1984; 87: 927-33.

16 Cameron AJ, Ott BJ, Payne WS. The incidence of adenocarcinoma in columnar-lined (Barrett's) esophagus. $N$ Engl J Med 1985; 313: 857-9.

17 Kaplan EL, Meier EA. Nonparametric estimation from incomplete observations. J Am Statist Assoc 1958; 53: 457-81.

18 Overledenen naar doodsoorzaak, leeftijd en geslacht in het jaar 1985. Serie Al, blad 5. Voorburg: Centraal Bureau voor de Statistiek, 1986.

19 Harle IA, Finley RJ, Belsheim M, et al. Management of adenocarcinoma in columnar-lined oesophagus. Ann Thorac Surg 1985; 40: 330-6.

20 Ronsom JM, Patel GK, Cliff SA, Womble NE, Read RC. Extended and limited types of Barrett's esophagus in the adult. Ann Thorac Surg 1982; 33: 19-27.

21 Shields HM. Barrett's oesophagus and carcinoma. Gastroenterology 1987; 93: 652-9.

22 Hamilton SR, Smith RRL. The relation between columnar epithelial dysplasia and invasive adenocarcinoma arising in Barrett's oesophagus. Am J Clin Pathol 1987; 87: 301-12.

23 Gillen P, Keeling P, Hennessy TPJ. Barrett's oesophagus: risk factors for malignancy [Abstract]. Gut 1987; 28: A1379.

24 Robertson CS, Mayberry JF, James PD, Atkinson M. Value of endoscopic surveillance in the early detection of malignant change in Barrett's oesophagus [Abstract]. Gut 1987; 28: A1379-80. 